\title{
THE BEHAVIOUR OF BENN'S P EXPONENT IN A SD-CLASSIFIED MODEL POPULATION NORMALLY DISTRIBUTED IN THE BODY WEIGHT AND THE HEIGHT
}

\author{
Boris NERUdA \\ Private Institute for Studies in Science and Medicine, 54585 Esch, Germany
}

\begin{abstract}
In this short communication the influence of classifying a model population into 5 different weight-height classes upon the exponent $\mathrm{p}$ of Benn's index $\left(\mathrm{W} / \mathrm{H}^{\mathrm{p}}\right)$ was studied. Such a classification stratifies data into subspecies with different physics. The Benn's index is known to be gender and also population specific, where figures for males range between 1.65 and 1.83 [2]. Therefore, it was hoped to discover a similar effect of such a classification on the expression of exponent $\mathrm{p}$ and it was expected to find some difference in exponent $\mathrm{p}$ at least between not neighbouring classes. This, however, was not the case, probably because the underlying population was constructed under strict assumptions, which do not prevail in biased ordinary populations.
\end{abstract}

Keywords: body mass indices, Benn's index, SD-classification, correlation, normal distribution

\section{MATERIAL, METHODS AND RESULTS}

A dataset of 20,000 elements was generated by using an algorithm published already earlier[4]. This allowed to model a population normally distributed in the body weight $(\mathrm{W}=77.0 \pm 12.3)$ and the stature $(\mathrm{H}=170.0 \pm 6.8)$ with a preset correlation $\left(\mathrm{r}_{\mathrm{wH}}=0.500\right)$ between these two variables, which would represent an adult male Caucasian population. As demanded, the figure for the correlation between $\mathrm{H}$ and $\mathrm{BMI}$ was low $\left(\mathrm{r}_{\mathrm{HBMI}}=0.008\right)$, but high between $\mathrm{W}$ and BMI $\left(\mathrm{r}_{\text {wBMI }}=0.864\right)$. 
After performing an SD-classification according to the well-established procedure inaugurated by $\mathrm{H}$. Kaarma [3] index $\mathrm{p}$ was calculated from the linear regression between the logarithms of $\mathrm{W}$ and $\mathrm{H}$ for each of the 5 groups. The entire sample had a $\mathrm{p}=2.002$, which separated into $\mathrm{p}=1.731$ for the pyknomorphs, $\mathrm{p}=1.916$ for the leptomorphs, $\mathrm{p}=2.151$ for the short, $\mathrm{p}=2.139$ for the medium, and $\mathrm{p}=2.154$ for the tall.

\section{DISCUSSION}

In the long row of the body mass indices used to characterize the obesity Benn's index [1] has the advantage to be completely independent from the stature, which is assumed to be one of the preconditions for using such an index. The model population of this study was constructed in such a way as to give a normal and not a typically skewed distribution of both variables, and a low $r_{\text {HвMr }}$ Starting with an exponent $\mathrm{p}=2.00$ not much of a change for the classified data was observed. Further studies will be needed to learn more about the impact of skewing and varying correlations between $\mathrm{W}$ and $\mathrm{H}$ in order to advance our knowledge on these and other parameters governing the system of body weightheight indices.

\section{REFERENCES}

1. Benn R. T. (1971). Some mathematical properties of weight-for-height indices used as measures of adiposity. Br J Prov Soc Med, 25, 42-50.

2. Garn S. M., Pesick S.D. (1982). Comparison of the Benn index and other body mass indices in nutritional assessment. Am J Clin Nutr, 32, 573-575.

3. Kaarma H. (1995). Complex statistical characterization of women's body measurements. Anthrop Anz 53, 239-244.

4. Neruda B., Hilger Y. (2010). Impact of the correlation between normally distributed samples of stature and body weight upon body mass index statistics. Papers Anthropol XIX, 271-278.

\section{Address for correspondence:}

Boris Neruda

Private Institute for Studies in Science and Medicine

54585 Esch, Germany

Eschbergstrasse 28 